\title{
Biomarkers to distinguish functional constipation from irritable bowel syndrome with constipation
}

\author{
W. E. WHITEHEAD, ${ }^{\star}$ O. S. PALSSON ${ }^{\star} \&$ M. SIMRÉN ${ }^{\star}, \dagger$ \\ *Center for Functional Gastrointestinal and Motility Disorders, University of North Carolina at Chapel Hill, Chapel Hill, NC, USA \\ $\dagger$ Department of Internal Medicine \& Clinical Nutrition, Institute of Medicine, Sahlgrenska Academy, University of Gothenburg, \\ Gothenburg, Sweden
}

\section{Key Points}

- Optimal treatments for functional constipation (FC) and irritable bowel syndrome with constipation (IBS-C) differ, but symptom criteria do not reliably distinguish between them; some regard FC and IBS-C as parts of a single constipation spectrum.

- Physiological studies show modest support for the hypothesis that decreased colonic motility and prolonged whole gut transit identify FC while pain hypersensitivity distinguishes IBS-C, but there is substantial overlap. Pelvic floor dyssynergia appears to be unrelated to symptom patterns in FC or IBS-C.

- A novel magnetic resonance imaging technique seems to reliably distinguish FC from IBS-C based on the response to an osmotic laxative.

\begin{abstract}
Treatments for functional constipation (FC) and irritable bowel syndrome with constipation (IBS-C) differ, but symptom criteria do not reliably distinguish between them; some regard FC and IBS-C as parts of $a$ single constipation spectrum. Our goal was to review studies comparing FC and IBS-C to identify possible biomarkers that separate them. A systematic review identified 15 studies that compared physiologic tests in FC vs IBS-C. Pain thresholds were lower in IBS-C than $F C$ for $3 / 5$ studies and not different in 2/5. Colonic motility was decreased more in FC than IBS$C$ for $3 / 3$ studies, and whole gut transit was delayed
\end{abstract}

\section{Address for Correspondence}

William E. Whitehead, Center for Functional Gastrointestinal and Motility Disorders, Campus Box 7080, Bioinformatics Building Room 4112, University of North Carolina at Chapel Hill, Chapel Hill, NC 27599-7080, USA.

Tel: +1 919843 6961; fax: +1 919843 2793;

e-mail: William_Whitehead@med.unc.edu

Received: 4 April 2016

Accepted for publication: 13 April 2016 more in FC than IBS-C in 3/8 studies and not different in 5/8. Pelvic floor dyssynergia was unrelated to diagnosis. Sympathetic arousal, measured in only one study, was greater in IBS-C than FC. The most reliable separation of FC from IBS-C was shown by a novel new magnetic resonance imaging technique described in this issue of the journal. These authors showed that drinking one liter of polyethylene glycol laxative significantly increased water content in the small intestine, volume of contents in the ascending colon, and time to first evacuation in FC Vs IBS-C; and resulted in less colon motility and delayed whole gut transit in FC compared to IBS-C. Although replication is needed, this well-tolerated, non-invasive test promises to become a new standard for differential diagnosis of FC VS IBS-C. These data suggest that FC and IBS-C are different disorders rather than points on a constipation spectrum.

Keywords biomarkers, functional constipation, irritable bowel syndrome with constipation, pelvic floor dyssynergia. 
Current symptom criteria do not reliably distinguish between functional constipation (FC) and irritable bowel syndrome with constipation (IBS-C), and some investigators regard them as parts of a single constipation spectrum. However, some treatments are thought to work better for one of these types of constipation than the other, so it is important to know whether there are ways of reliably distinguishing between them. Moreover, it is important to know whether there are different pathophysiological mechanisms accounting for these two types of constipation because they may represent different targets for drug development. Our goal was to review studies comparing groups of patients diagnosed FC and IBS-C to identify possible biomarkers that separate them.

The study in this issue of Neurogastroenterology and Motility by the Nottingham group ${ }^{1}$ may be remembered as a turning point in the controversy over whether FC and IBS-C are two distinct disorders or parts of a spectrum of symptoms related to a shared pathophysiology. This study was able to show significant differences between well-characterized groups of patients with FC and IBS-C in whole gut transit time, colonic motility, water content in the small intestine, and colon volumes using validated, novel, non-invasive magnetic resonance imaging (MRI) techniques. The authors suggest that these are biomarkers for the differential diagnosis of subtypes of constipation. Future research may make it possible to individualize treatment based on these biomarkers.

Some of the unique strengths of this study and of the MRI techniques described are listed below:

1. These MRI-based physiological tests are better accepted by patients than are traditional physiological tests, such as pressure measurements made with intraluminal motility catheters, barostat balloons, abdominal radiographs of the transit of radiopaque markers, or gamma cameras, to assess the progression of radioisotopes. Because these MRI investigations are better tolerated, they are less likely to bias the data due to the unwillingness of some patients to undergo invasive testing or their apprehension during the tests.

2. The investigators assessed the physiological response to a standardized provocative stimulus, namely the ingestion of a liter of an osmotic laxative consisting of polyethylene glycol and electrolytes in a commercially available preparation. This minimizes measurement error due to variability in physiological responses from day to day, which may confound purely observational studies.

3. These MRI-based tests of transit, motility, and volume of water in the small bowel and colon were all previously validated in normal controls with the result that normal ranges and reproducibility are known. ${ }^{2-6}$ Moreover, the sensitivity of MRI measures of colon and small bowel volumes has been shown by comparing the effects of ingesting different food types on the volume and distribution of gas and water in the gut. ${ }^{7}$

\section{SYMPTOM-BASED CLASSIFICATION OF CONSTIPATION SUBTYPES}

Constipation is a symptom (not a disease), which may present in several different phenotypes. The Rome III criteria ${ }^{8}$ rely on history and symptoms to distinguish between two major categories of constipation: IBS-C and FC. Patients are classified as IBS-C if they have abdominal pain at least 3 days a month in addition to symptoms of constipation, or as FC if they have at least two of six symptoms of difficult or infrequent defecation occurring $25 \%$ of the time and insufficient pain to qualify for a diagnosis of IBS. The Rome III criteria did not permit a patient who met criteria for IBS-C to be diagnosed with comorbid FC, that is, overlap between IBS-C and FC was not permitted. The recently released update to the Rome diagnostic criteria (Rome IV) ${ }^{9}$ make no significant changes to the diagnostic criteria for IBS-C and FC; although the experts that reviewed and updated the Rome diagnostic criteria concluded, based on a review of recent new data, that IBS-C and FC are probably different parts of a spectrum of symptoms of constipation rather than distinct disorders, they did not modify the Rome III approach of classifying these as independent, and mutually exclusive diagnoses.

The pivotal study which led the Rome IV bowel committee to re-evaluate the distinction between IBS$\mathrm{C}$ and FC was reported by Wong and colleagues. ${ }^{10}$ These investigators administered the Rome III Diagnostic Questionnaire to 1707 adult patients in a large health maintenance organization. The symptom survey was administered on two occasions 12 months apart. Using the Rome III criteria, they identified 231 patients with FC and 201 with IBS-C in the initial survey. Key findings were: (i) When the Rome III (also the Rome IV) requirement that patients meeting criteria for IBS-C cannot also be diagnosed FC was suspended, $90 \%$ of IBS-C cases met criteria for FC and $44 \%$ of FC cases met criteria for IBS-C. (ii) When the official Rome III criteria were again employed, there were no qualitative differences between FC and IBS-C: $45 \%$ of FC patients reported some abdominal pain, and the IBSC patients were found to have more symptoms of difficult or infrequent defecations than the FC patients. (iii) When the patients diagnosed as FC or IBS-C were reassessed 1 year later, $1 / 3$ of patients in each group 
switched to the other diagnosis if they continued to have symptoms of constipation. Wong and colleagues concluded that patients identified by the Rome III criteria as FC and IBS-C are not distinct groups. Several other studies reached similar conclusions. ${ }^{11}$

Other evidence ${ }^{12}$ suggests that practicing gastroenterologists may not regard FC and IBS-C as mutually exclusive diagnoses: We sought to validate the Rome IV criteria for FC by comparing the clinical diagnoses of experienced gastroenterologists from nine sites with the diagnoses assigned to their patients based on the Rome IV Diagnostic Questionnaire completed by the patient independently following their clinic visit. When the Rome IV requirement that FC could not be diagnosed if the patient fulfilled Rome IV criteria for IBS was followed, only $32 \%$ of patients who received a clinical diagnosis of FC were classified FC by the Rome IV criteria. However, if overlap between IBS-C and FC was allowed, $73 \%$ of clinically diagnosed patients with chronic constipation fulfilled the Rome IV criteria for FC.

\section{PATHOPHYSIOLOGICAL MECHANISMS FOR THE SYMPTOMS OF IBS AND FC}

\section{Pain sensitivity}

The defining symptom of IBS, and the symptom which distinguishes IBS-C from FC according to the Rome IV criteria, ${ }^{9}$ is abdominal pain. As a group, IBS patients have increased visceral pain sensitivity as reflected in a lower threshold of rectal or colonic distension to report pain (allodynia) ${ }^{13-17}$ and a greater intensity of pain for a specified level of colorectal distention within the noxious range (hyperalgesia). ${ }^{17,18}$ However, there is an overlap between IBS patients and healthy controls in pain sensitivity, and the correlation between the pain threshold and the frequency and intensity of clinically reported abdominal pain is modest. ${ }^{15,17}$ One explanation for this modest correlation between physiological measures of pain sensitivity and symptoms of abdominal pain is that increased sensitivity requires a distention stimulus such as accumulated stool or gas to trigger an actual pain sensation in a pain sensitive subject. Nevertheless, we would expect increased visceral pain sensitivity to discriminate patients with IBS-C from those with FC.

\section{Delayed whole gut transit}

The mechanism that is believed to account for infrequent passage of stools is impaired peristaltic motility in the colon or small intestine due to decreased amplitudes and/or non-peristaltic patterns of contractions and/or deficient numbers of high-amplitude aborally propagating contractions. ${ }^{19}$ However, intestinal motility is difficult to measure directly, so the time required for transit of indigestible markers or radioisotopes is used as a surrogate marker of abnormal intestinal motility. The hypothesis is that prolonged whole gut transit should discriminate FC from IBS-C.

\section{Pelvic floor dysfunction}

The symptom of difficult evacuation of stool from the rectum is often attributed to one of two mechanisms: (i) paradoxical contraction or failure to relax the pelvic floor muscles, and/or (ii) inadequate increases in rectal pressure (i.e., a negative rectal-to-anal canal pressure gradient) during attempts to defecate. Many terms have been used to characterize this phenomenon (e.g., anismus, pelvic floor dyssynergia, dyssynergic defecation), but the Rome IV criteria use the umbrella term, functional defecation disorder, to refer to difficult defecation from either cause, and they distinguish two subtypes based on which one of two mechanisms is in play: dyssynergic defecation or inadequate rectal propulsion. ${ }^{20}$ Dyssynergic defecation and inadequate rectal propulsion are usually assessed by anorectal manometry or by pelvic floor electromyography (EMG). The balloon evacuation test is a measure of the time required for subjects to evacuate a water- or air-filled balloon from the rectum, and it is regarded as a measure of pelvic floor dysfunction. ${ }^{21}$ Our hypothesis is that functional defecation disorder is a subtype of FC and that the physiological measures referred to above (anal canal pressure, pelvic floor EMG, intra-abdominal pressure during efforts to evacuate and the balloon evacuation test) should discriminate patients with FC from patients with IBS-C. However, we acknowledge that there is currently some controversy over whether functional defecation disorder is more closely linked to IBS-C than to FC. ${ }^{22}$

\section{Other pathophysiological mechanisms for constipation}

Additional physiological risk factors have been proposed for the symptom of constipation including the side-effects of opiate or anticholinergic medications, inadequate fiber and water in the diet, and decreased intestinal secretion. However, this discussion will focus on the three mechanisms listed above.

\section{REVIEW OF STUDIES COMPARING IBS-C TO FC}

Table 1 and Fig. 1 summarize the 15 studies identified by a systematic search of PubMed using the terms 
Table 1 Summaries of studies comparing FC to IBS-C

\begin{tabular}{|c|c|c|c|}
\hline Study & Population & Measures & Results \\
\hline Mertz $z^{23,24}$ & $\begin{array}{l}131 \text { patients with refractory } \\
\text { constipation including } 107 \text { ( } 82 \%) \\
\text { who met criteria for IBS. } \\
\text { Physiological data were not } \\
\text { analyzed by Rome diagnoses, but } \\
\text { by symptom clusters derived from } \\
\text { principal components analysis. }\end{array}$ & $\begin{array}{l}\text { Symptom checklist, WGT (Sitzmark } \\
\text { transit test); PainTh by barostat; } \\
\text { DYS by anorectal manometry and } \\
\text { EMG combined }\end{array}$ & $\begin{array}{l}\text { Delayed WGT, visceral hypersensitivity, and } \\
\text { DYS frequently overlaped but were not } \\
\text { significantly correlated. Factor analysis } \\
\text { identified four symptom clusters: IBS-C, } \\
\text { slow transit constipation (STC), functional } \\
\text { defecation disorder, and normal transit. } \\
\text { IBS-C correlated with discomfort threshold } \\
\text { and STC symptom cluster correlated with } \\
\text { WGT, but FDD cluster of symptoms did } \\
\text { not correlate with DYS. }\end{array}$ \\
\hline Bouin $^{16}$ & $\begin{array}{l}86 \text { IBS (all subtypes), } 26 \text { FC, } 21 \\
\text { Functional Dyspepsia, } 31 \\
\text { miscellaneous FGIDs, } 25 \mathrm{HV}\end{array}$ & $\begin{array}{l}\text { PainTh: Progressively larger } \\
\text { intermittent phasic distentions by } \\
\text { barostat. Calculated sensitivity, } \\
\text { specificity, and PPV of } \\
\text { discriminating between groups. }\end{array}$ & $\begin{array}{l}\text { PainTh: Best discrimination of IBS from all } \\
\text { other FGID patients and from HV was } \\
40 \mathrm{mmHg} \text {. Sensitivity }=95.5 \% \\
\text { specificity }=71.8 \%, \mathrm{PPV}=85.4 \%\end{array}$ \\
\hline Bassotti $^{19}$ & $35 \mathrm{STC}, 10 \mathrm{IBS}-\mathrm{C}, 18 \mathrm{HV}$ & $\begin{array}{l}\text { Motility: High amplitude propagated } \\
\text { contractions (HAPC)/24 h; Low } \\
\text { amplitude propagated contractions } \\
\text { (LAPC) } / 24 \mathrm{~h} \text {, response to meal }\end{array}$ & $\begin{array}{l}\text { Motility: STC and IBS-C had fewer HAPCs } \\
\text { than HV ( } 1.5 \text { vs } 3.7 \text { vs } 6.0) \text {. STC had fewer } \\
\text { LAPCs than IBS-C (46 vs 87.4). Meal } \\
\text { stimulated LAPCs in all three groups. }\end{array}$ \\
\hline Walter $^{25}$ & $\begin{array}{l}27 \text { IBS (most with loose stools), } \\
13 \mathrm{FC}, 18 \mathrm{HV}\end{array}$ & $\begin{array}{l}\text { Sympathetic activity: Skin } \\
\text { conductance (SC) measured on foot. } \\
\text { Phasic distentions by barostat to } \\
\text { determine thresholds for first } \\
\text { sensation, urge, and maximum } \\
\text { tolerable volume; and habituation } \\
\text { of SC response to repeated } \\
\text { distentions }\end{array}$ & $\begin{array}{l}\text { Sympathetic activation: At baseline SC } \\
\text { higher in IBS vS HV and lower in FC vS HV. } \\
\text { All sensory thresholds were lower in IBS-C } \\
\text { than in FC. SC response to distention was } \\
\text { higher in IBS vS HV and habituated } \\
\text { over trials. }\end{array}$ \\
\hline Hasler $^{26}$ & 12 IBS-C, 24 FC, $53 \mathrm{HV}$ & $\begin{array}{l}\text { Motility: Number of contractions } \\
\text { measured by wireless motility } \\
\text { capsule }\end{array}$ & $\begin{array}{l}\text { Motility: IBS-C had more contractions than } \\
\text { FC or HV. FC was not significantly } \\
\text { different from HV. }\end{array}$ \\
\hline Suttor $^{27}$ & 29 FDD + IBS, 21 FDD - IBS & $\begin{array}{l}\text { WGT; DYS assessed by ARM; BET; } \\
\text { PainTh: sensory thresholds; } \\
\text { response to biofeedback }\end{array}$ & $\begin{array}{l}\text { WGT: no difference between groups; } \\
\text { PainTh: no difference; BET: no difference; } \\
\text { DYS: no difference; response to } \\
\text { biofeedback: no difference but IBS } \\
\text { symptoms improved after pelvic floor } \\
\text { biofeedback }\end{array}$ \\
\hline Ansari $^{28}$ & $\begin{array}{l}25 \text { FC vs } 25 \text { non-diarrhea } \\
\text { predominant IBS }\end{array}$ & DYS; BET & $\begin{array}{l}\text { DYS: more prevalent in FC than IBS; BET: } \\
\text { more abnormalities in IBS than FC }\end{array}$ \\
\hline Patcharatrakul $^{29}$ & 50 FC vs 50 IBS-C & WGT, segmental transit time & $\begin{array}{l}\text { WGT: no significant difference but a trend } \\
\text { with } 52.2 \mathrm{~h} \text { for FC and } 41.2 \mathrm{~h} \text { for IBS-C; } \\
\text { rectosigmoid transit slower for FC than IBS- } \\
\mathrm{C}(19.9 \mathrm{~h} \text { vs } 11.9 \mathrm{~h})\end{array}$ \\
\hline Bouchoucha $^{30}$ & $\begin{array}{l}50 \text { HV, } 43 \text { FC, } 46 \text { IBS-C, } 15 \\
\text { IBS-M, } 13 \text { IBS-D, } 10 \text { FD }\end{array}$ & $\begin{array}{l}\text { Fasting WGT, change in WGT before } \\
\text { to after } 1000 \text { cal meal, meal-related } \\
\text { symptoms }\end{array}$ & $\begin{array}{l}\text { WGT: slower in FC than IBS-C }(84.1 \mathrm{~h} \text { vs } \\
49.4 \mathrm{~h}) . \text { Minimal differences in response to } \\
\text { eating }\end{array}$ \\
\hline Shekhar ${ }^{31}$ & $11 \mathrm{FC}, 23 \mathrm{IBS}-\mathrm{C}, 23 \mathrm{HV}$ & WGT; SBTT; PaintTh; plasma 5-HT & $\begin{array}{l}\text { WGT: no difference between IBS-C and FC; } \\
\text { both greater than HV. PainTh: IBS-C lower } \\
\text { than FC or HV. 5-HT: IBS-C lower than FC } \\
\text { or HV. }\end{array}$ \\
\hline Bouchoucha $^{32}$ & 66 IBS-C, 62 FC & $\begin{array}{l}\text { WGT, segmental transit time; DYS; } \\
\text { discomfort threshold }\end{array}$ & $\begin{array}{l}\text { WGT: no significant difference }(71 \mathrm{~h} \text { for FC } \\
\text { vs } 60 \mathrm{~h} \text { for IBS-C). DYS: more frequent in } \\
\text { IBS-C ( } 56 \% \text { vs } 37 \%) \text {. PainTh: no difference } \\
\text { between FC vs IBS-C ( } 238 \mathrm{~mL} \text { vs } 241 \mathrm{~mL}) \text {. }\end{array}$ \\
\hline Park $^{33}$ & 88 FC, 57 IBS-C & WGT; gas volume in colon & $\begin{array}{l}\text { WGT: no significant difference between IBS- } \\
\mathrm{C} \text { and FC }(38.4 \mathrm{~h} \text { vs } 43.8 \mathrm{~h} \text { ). Gas volume: } \\
\text { no difference between FC and IBS-C. }\end{array}$ \\
\hline Bouchoucha $^{34}$ & 210 IBS-C, 194 FC & $\begin{array}{l}\text { WGT; 'difficult defecation' defined } \\
\text { by }>2 \text { symptoms of straining, } \\
\text { incomplete evacuation, anal } \\
\text { blockage, digital maneuvers }\end{array}$ & $\begin{array}{l}\text { WGT: no difference overall between FC and } \\
\text { IBS-C ( } 59.4 \mathrm{~h} \text { vs } 58.6 \mathrm{~h}) \text {. Symptoms of } \\
\text { difficult defecation: more frequent in IBS-C } \\
(84 \%) \text { than FC }(68 \%) \text {. In FC but not IBS-C, } \\
\text { patients with difficult defecation } \\
\text { symptoms had slower WGT than those } \\
\text { without ( } 61.5 \mathrm{~h} \text { vs } 50.9 \mathrm{~h}) \text {. }\end{array}$ \\
\hline
\end{tabular}

(Continued.) 
Table 1 (continued)

\begin{tabular}{|c|c|c|c|}
\hline Study & Population & Measures & Results \\
\hline $\mathrm{Lam}^{1}$ & $24 \mathrm{FC}, 24$ IBS-C & $\begin{array}{l}\text { WGT by MRI marker, Motility by } \\
\text { variability in luminal diameter, } \\
\text { bloating sensitivity, small bowel } \\
\text { water content; colonic volumes. All } \\
\text { measured at baseline and following } \\
1 \mathrm{~L} \text { of Moviprep }\end{array}$ & $\begin{array}{l}\text { WGT: Slower in FC than IBS-C; Motility: } \\
\text { less in FC vs IBS-C; Time to first } \\
\text { defecation: longer in FC vs IBS-C; Visceral } \\
\text { sensitivity to bloating: no difference; Small } \\
\text { bowel water content and ascending colonic } \\
\text { volume: greater for FC than IBS-C. }\end{array}$ \\
\hline
\end{tabular}

FC, functional constipation; IBS, irritable bowel syndrome; IBS-C, irritable bowel syndrome with constipation; FDD, functional defecation disorder; STC, slow transit constipation; FGID, functional gastrointestinal disorder; HV, healthy volunteers; ARM, anorectal pressure measurements; BET, balloon evacuation test; WGT, whole gut (i.e., mouth to anus) transit time; DYS, dyssynergic defecation (defined by paradoxical contraction when pushing to evacuate and measured by anorectal manometry or electromyography); PainTh, rectal threshold pressure or volume for pain or discomfort; SBTT, small bowel transit time; MRI, magnetic resonance imaging; SC, skin conductance (a measure of sympathetic arousal); 5-HT, 5hydroxytryptamine (serotonin).

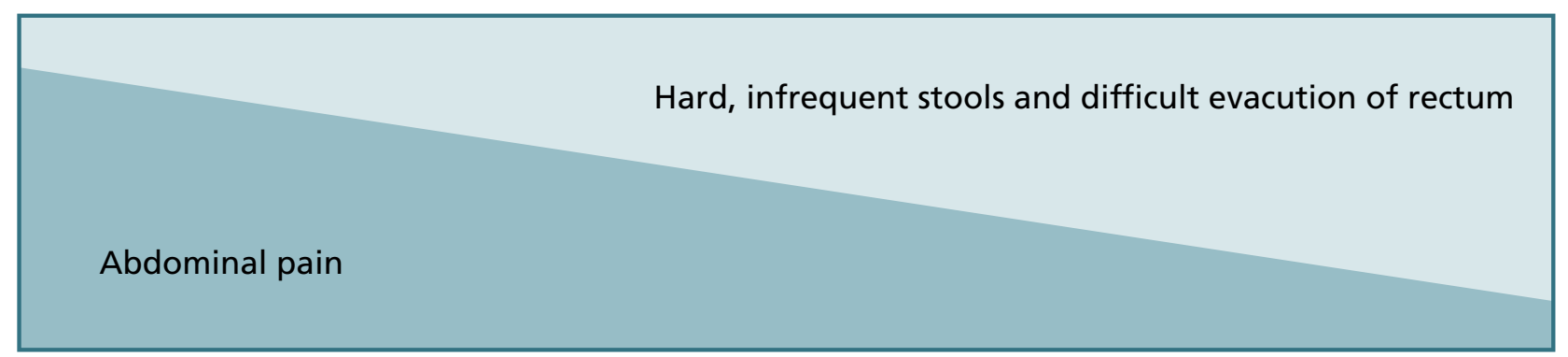

\begin{tabular}{|cc|}
\hline IBS with & Functional \\
constipation & constipation \\
(IBS-C) & (FC) \\
\hline
\end{tabular}

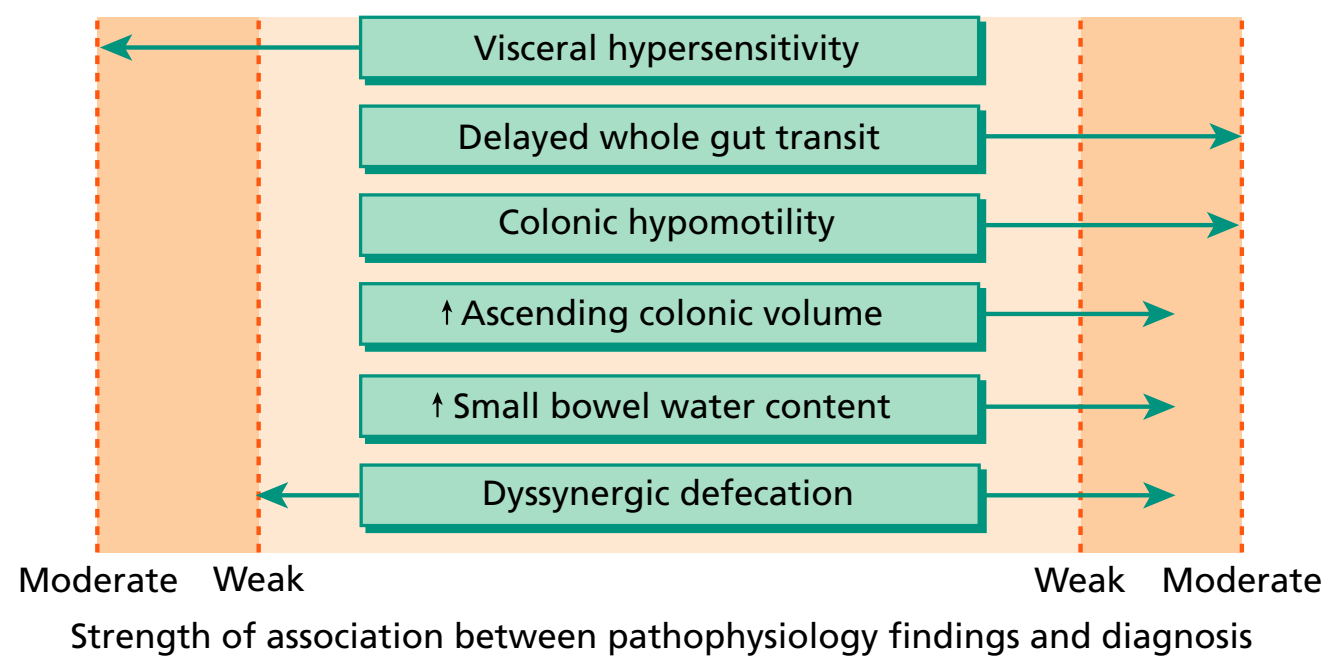

Figure 1 Schematic drawing demonstrating the symptom-based spectrum of functional constipation and irritable bowel syndrome with constipation, and biomarkers that may be used to discriminate these conditions from each other. For further details, please see text.

(functional constipation or chronic constipation or idiopathic constipation) and (irritable bowel syndrome or IBS) and (physiological mechanism, or whole gut transit or Sitzmarks or motility or visceral hypersensitivity or biomarker or disordered defecation or dyssynergic defecation or outlet dysfunction or anismus). We screened titles and then abstracts to identify articles of relevance to the topic. A requirement was that the study had to directly compare separate patient groups with FC or IBS-C. The search was not limited to 
English language publications, but all the studies meeting inclusion criteria were published in English.

\section{Whole gut transit and motility}

Eight studies in Table 1 compared whole gut transit (WGT) in FC vs IBS-C. The hypothesis was that transit time would be slower in FC than in IBS-C, and this was found in 3/8 studies. ${ }^{1,29,30}$ In five other studies ${ }^{27,31-34}$ there was no statistically significant difference between FC and IBS-C, even though some of these studies found trends of differences between the groups in the expected direction. There were no studies that showed slower transit in IBS-C compared to FC, which suggests that there is a trend favoring the hypothesis. Motility of the colon was measured in three studies, ${ }^{1,19,26}$ and all three showed less motility in FC compared to IBS-C, which was the hypothesized outcome.

\section{Pain thresholds}

Visceral pain sensitivity was measured in four studies, ${ }^{16,27,31,32}$ and maximum tolerable volume was measured in one study. ${ }^{25}$ Three studies showed the expected lower pain threshold in IBS-C compared to FC. ${ }^{16,25,31}$ None of these five studies showed lower pain thresholds in FC compared to IBS-C, again suggesting a trend that favors the hypothesis of a specific association between visceral pain sensitivity and IBS.

\section{Dyssynergic defecation}

This was measured in three studies: Dyssynergic defecation was more prevalent in FC than in IBS-C, as hypothesized, for one study, ${ }^{28}$ but was no different in one study ${ }^{27}$ and was paradoxically more prevalent in IBS-C than in FC in the third study. ${ }^{32}$ The balloon evacuation test, which is an alternative measure believed to reflect functional defecation disorder, was tested in two studies: there was no difference between IBS-C and FC in one of these studies, ${ }^{27}$ and abnormal balloon evacuation was unexpectedly more common in IBS-C than in FC in the other study. ${ }^{28}$ Thus, there is no apparent trend favoring the hypothesis that dyssynergic defecation or inability to evacuate a simulated stool should be more common in FC compared to IBS-C.

\section{Serotonin signaling}

The Shekhar study ${ }^{31}$ found plasma 5-HT levels to be lower in IBS-C compared to FC. Other studies which measured serotonin in mucosal biopsies likewise suggest that serotonin signaling differs in FC vs IBS-C:
Costeido et al. ${ }^{35}$ reported elevated synthesis and release of 5-HT in FC, in contrast to a previous study from this group ${ }^{36}$ which reported decreased 5-HT and SERT in IBS-C. These authors suggest that there may be increased 5-HT availability in the lamina propria in both types of constipation, although the mechanisms differ: increased synthesis in FC, and decreased clearance in IBS-C. However, other studies ${ }^{37}$ have reported different findings, so 5-HT signaling pathways cannot yet be regarded as a reliable biomarker separating FC from IBS-C.

\section{Correlations between biomarkers}

The study design in 14 of the 15 studies reviewed is problematic because physiological findings were compared between groups of patients who were classified as FC or IBS-C on the basis of symptom criteria, and symptom criteria have been shown to be unreliable for classification of patients into these groups. ${ }^{11}$ Only one study used a design that avoids this confounding factor: Mertz and colleagues ${ }^{23}$ recruited 131 patients referred for refractory constipation and assessed multiple physiological measures in all of them. If FC and IBS-C are on a spectrum but have a shared pathophysiology, one might expect to find a positive correlation between pain sensitivity and transit time or dyssynergia, but instead the investigators found these biomarkers to be uncorrelated and independent of each other. There were groups of patients in whom these biomarkers overlapped, but the frequency with which this occurred was no greater than expected by chance.

\section{DISCUSSION}

The purpose of our review was to determine whether the physiological mechanisms that have been proposed for IBS and the two major subtypes of constipation (slow transit constipation and functional defecation disorder) can be regarded as biomarkers that identify distinct groups of patients corresponding to IBS-C and FC. The physiological markers investigated were pain sensitivity, colonic motility (measured by whole gut transit or different techniques to measure colonic contractions), pelvic floor dyssynergia or inadequate rectal propulsion pressure during attempted defecation, and the balloon evacuation test. As is evident from Table 1, the literature does not provide an unambiguous answer to this question. There is heterogeneity of findings among the studies with some showing the expected associations between visceral pain hypersensitivity and IBS-C, and between delayed transit or 
decreased colonic motility and FC. However, other studies showed no difference between clinically diagnosed groups with IBS-C and FC on these measures.

The study by Lam et al. in this issue ${ }^{1}$ of the journal identifies three additional physiological measures that are proposed as biomarkers to separate FC from IBS-C, namely the time to first evacuation, volume of water in the small intestine, and volume of the ascending colon following ingestion of a liter of an osmotic laxative (polyethylene glycol). A novel aspect of the Lam study is that the authors assessed the response to a provocative stimulus (ingestion of an osmotic laxative) rather than attempting to find physiological differences under baseline conditions. The response to a standardized provocative stimulus likely increases the signal to noise ratio and leads to more reliable separation of diagnostic groups.

The physiological significance of the differences in small intestinal and colonic volumes following laxative ingestion is unclear. It seems likely that differences in colonic and small bowel motility and in time to first evacuation contribute to these differences in water volume, but differences in the secretion and absorption of water by the small intestine and colon are also possibilities.

The relatively weak separation between IBS-C and FC in the studies reviewed in Table 1 could be explained by several factors: (i) In 14 of these 15 studies, patients were classified into groups based on symptom criteria which have been shown to be unreliable for separating patients into distinct groups. ${ }^{11}$ Consequently, one would expect some overlap between IBS-C and FC when these groups are compared on physiological measures. (ii) With the exception of the recent study by Lam and colleagues, these studies measured physiological differences under baseline conditions rather than in response to a standardized physiological stimulus such as a laxative or a meal. (iii) Most of the studies in Table 1 did not distinguish between slow transit constipation and functional defecation disorder, but instead assumed that FC is a homogeneous disorder. Recognizing that subtypes of FC may have different physiological mechanisms might improve their discrimination from IBS-C.

The studies in Table 1 provide no support for the hypothesis that dyssynergic defecation (paradoxical contraction or failure to relax pelvic floor muscles during defecation) or the related balloon evacuation test of the ability to evacuate a water-filled balloon are more common in FC than in IBS-C; there is even weak evidence for a trend in the opposite direction. Although this outcome was unexpected by the reviewers, it is consistent with the speculation of some authors that dyssynergic defecation can give rise to symptoms that are indistinguishable from IBS-C, namely rectal pain or discomfort that is relieved by defecation. ${ }^{27,38}$ Other investigators have found that pelvic floor dyssynergia is not only seen in patients with difficult evacuation but is also found in healthy controls. ${ }^{39,40}$ However, we have previously shown that the presence of dyssynergic defecation in patients meeting criteria for $\mathrm{FC}$ is a strong predictor of which patients will benefit from biofeedback therapy to teach patients how to relax the pelvic floor during attempted defecation. ${ }^{41,42}$ This remains an unresolved question which will require additional research.

Future studies investigating whether IBS-C and FC are distinct disorders or parts of a spectrum of symptoms with a shared pathophysiology should consider the following alternative study designs: (i) Assess all physiological mechanisms for abdominal pain and/or constipation in the same patients regardless of whether they meet $a$ priori symptom criteria for IBS-C or FC, and then look for objective evidence of overlap in the physiological basis for these symptoms. This is the approach pioneered by Mertz et al. ${ }^{23}$ The absence of a correlation between pain sensitivity, whole gut transit, motility, and pelvic floor dyssynergia in the Mertz study provides persuasive evidence for the independence of IBS-C and FC, even though more supportive studies are needed. (ii) Measure physiological responses not only under baseline conditions but also after a provocative stimulus such as a laxative, ${ }^{1}$ ingestion of a provocative meal, ${ }^{43-45}$ or intraluminal distention ${ }^{15}$; this may reduce measurement variability. (iii) Incorporate differential responses to treatment as part of the test battery. For example, it is known that antidepressants may be more effective for reducing abdominal pain than for increasing stool frequency, and that pelvic floor biofeedback is more effective in constipated patients who exhibit dyssynergic defecation and/ or failure to evacuate a water-filled balloon. ${ }^{41,42,46}$ Consequently, identifying physiological tests that predict the response to treatment classes may be very helpful in separating patients into meaningful subgroups.

A limitation of the Lam study ${ }^{1}$ was the absence of a credible measure of pain sensitivity. The authors reported a measure of sensitivity for bloating, defined as the ratio of the maximum bloating sensation score following ingestion of a liter of polyethylene glycol to the total colonic volume, but this does not test the hypothesis that visceral pain sensitivity is increased in IBS-C compared to FC. The authors apparently decided to compute a sensitivity index for bloating only because, 
in a preliminary study in healthy controls, they observed a significant correlation between visual analog scale ratings of bloating sensation and colonic volumes, but the correlations between pain/discomfort ratings and colonic volumes were not significant. In the study reported in this issue, Lam and colleagues saw no differences between IBS-C and FC groups on the bloating sensitivity index and no significant correlation between bloating sensation ratings and colonic volumes. Despite this limitation, the MRI imaging protocol described by Lam et al. is the most promising method currently available for discriminating IBS-C from FC on the basis of physiology.

Identifying biological markers (or symptom criteria) that can reliably discriminate between IBS-C and subtypes of FC is clinically important because these forms of constipation respond to different treatments. ${ }^{47}$ Antidepressants, cognitive behavior therapy, and hypnotherapy are techniques that significantly improve IBS symptoms including the symptoms of IBS-C, but they are not known to improve the symptoms of FC. On the other hand, the prokinetic drug prucalopride improves FC without proven benefits for IBS-C, and pelvic floor biofeedback improves functional defecation disorder without significant benefits for slow transit constipation. ${ }^{41}$ Our review of the published literature on biomarkers for constipation suggests that whole gut transit time and pain thresholds have reasonable specificity but modest sensitivity for differentiating FC and IBS-C, and that measures of pelvic floor dysfunction are of limited utility for this purpose. The quest for reliable biomarkers will likely continue, but the study from the Nottingham group ${ }^{1}$ identifies a promising new approach to accomplish this goal.

\section{FUNDING}

No funding declared.

\section{DISCLOSURE}

No competing dinterests declared.

\section{REFERENCES}

1 Lam C, Chaddock G, Marciani L, Costigan C, Paul J, Cox E, Hoad C, Menys A et al. Colonic response to laxative ingestion as assessed by MRI differs in constipated irritable bowel syndrome compared to functional constipation. Neurogastroenterol Motil. 2016. doi: 10.1111/nmo.12784. [Epub ahead of print] PubMed PMID: 26871949.

2 Hoad CL, Marciani L, Foley S, Totman JJ, Wright J, Bush D, Cox EF, Campbell E et al. Non-invasive quantification of small bowel water content by MRI: a validation study. Phys Med Biol 2007; 52: 6909-22.

3 Pritchard SE, Marciani L, Garsed KC, Hoad CL, Thongborisute W, Roberts E, Gowland PA, Spiller RC et al. Fasting and postprandial volumes of the undisturbed colon: normal values and changes in diarrhea-predominant irritable bowel syndrome measured using serial MRI. Neurogastroenterol Motil 2014; 26: 124-30.

4 Menys A, Hamy V, Makanyanga J, Hoad C, Gowland P, Odille F, Taylor SA, Atkinson D. Dual registration of abdominal motion for motility assessment in free-breathing data sets acquired using dynamic MRI. Phys Med Biol 2014; 59: 4603-19.
5 Chaddock G, Lam C, Hoad CL, Costigan C, Cox EF, Placidi E, Thexton E, Wright $J$ et al. Novel MRI tests of orocecal transit time and whole gut transit time: studies in normal subjects. Neurogastroenterol Motil 2014; 26: 205-14.

6 Marciani L, Garsed KC, Hoad CL, Fields A, Fordham I, Pritchard SE, Placidi E, Murray K et al. Stimulation of colonic motility by oral PEG electrolyte bowel preparation assessed by MRI: comparison of split vs single dose. Neurogastroenterol Motil 2014, 26: 1426-36.

7 Murray K, Wilkinson-Smith V, Hoad C, Costigan C, Cox E, Lam C, Marciani L, Gowland P et al. Differential effects of FODMAPs (fermentable oligo-, di-, mono-saccharides and polyols) on small and large intestinal contents in healthy subjects shown by MRI. Am J Gastroenterol 2014; 109: 110-9.

8 Longstreth GF, Thompson WG, Chey WD, Houghton LA, Mearin F, Spiller RC. Functional bowel disorders. Gas troenterology 2006; 130: 1480-91.

9 Lacey BE, Mearin F, Chang L, Chey WD, Lembo AJ, Simren M, Spiller R. Bowel disorders. Gastroenterology 2016; 150: 1393-407.

10 Wong RK, Palsson OS, Turner MJ, Levy R, Feld AD, Von Korff $M$, Whitehead WE. Inability of the Rome
III criteria to distinguish functional constipation from constipation subtype irritable bowel syndrome. Am I Gastroenterol 2010; 105: 2228-34.

11 Siah KTHW, Wong RK, Whitehead WE. Chronic constipation and constipation-predominant IBS: separate and distinct disorders or a spectrum of disease? Gastroenteol Hepatol 2016; 12: in press.

12 Palsson OS, Whitehead WE, van Tilburg MAL, Chang L, Chey W, Crowell MD, Keefer L, Lembo AJ et al. Development and validation of the Rome IV Diagnostic Questionnaire for adults. Gastroenteology 2016; 150: 1481-91.

13 Whitehead WE, Engel BT, Schuster MM. Irritable bowel syndrome: physiological and psychological differences between diarrhea-predominant and constipation-predominant patients. Dig Dis Sci 1980; 25: 404-13.

14 Whitehead WE, Holtkotter B, Enck P, Hoelzl R, Holmes KD, Anthony J, Shabsin HS, Schuster MM et al. Tolerance for rectosigmoid distention in irritable bowel syndrome. Gastroenterology 1990; 98(5 Pt 1): 1187-92.

15 Kanazawa M, Palsson OS, Thiwan SI, Turner MJ, van Tilburg MA, Gangarosa LM, Chitkara DK, Fukudo S et al. Contributions of pain sensitivity and colonic motility to IBS 
symptom severity and predominant bowel habits. Am I Gastroenterol 2008; 103: 2550-61.

16 Bouin $M$, Plourde V, Boivin $M$, Riberdy M, Lupien F, Laganiere $M$, Verrier P, Poitras P. Rectal distention testing in patients with irritable bowel syndrome: sensitivity, specificity, and predictive values of pain sensory thresholds. Gastroenterology 2002; 122: 1771-7.

17 Posserud I, Syrous A, Lindstrom L, Tack J, Abrahamsson H, Simren M. Altered rectal perception in irritable bowel syndrome is associated with symptom severity. Gastroenterology 2007; 133: 1113-23.

18 Camilleri M, McKinzie S, Busciglio I, Low PA, Sweetser S, Burton D, Baxter $\mathrm{K}$, Ryks $\mathrm{M}$ et al. Prospective study of motor, sensory, psychologic, and autonomic functions in patients with irritable bowel syndrome. Clin Gastroenterol Hepatol 2008; 6: 772-81.

19 Bassotti G, Chistolini F, Marinozzi G, Morelli A. Abnormal colonic propagated activity in patients with slow transit constipation and constipationpredominant irritable bowel syndrome. Digestion 2003; 68: 178-83.

20 Rao SSC, Bharucha AE, Chiarioni G, Felt-Bersma R, Knowles C, Malcolm A, Wald A. Anorectal disorders. Gastroenteology 2016; 150: 1430-42.

21 Chiarioni G, Kim SM, Vantini I, Whitehead WE. Validation of the balloon evacuation test: reproducibility and agreement with findings from anorectal manometry and electromyography. Clin Gastroenterol Hepatol 2014; 12: 2049-54.

22 Wald A, Bharucha AE, Cosman BC, Whitehead WE. ACG clinical guideline: management of benign anorectal disorders. Am I Gastroenterol 2014; 109: 1141-57.

23 Mertz H, Naliboff B, Mayer E. Physiology of refractory chronic constipation. Am I Gastroenterol 1999; 94: 609-15.

24 Mertz H, Naliboff B, Mayer EA. Symptoms and physiology in severe chronic constipation. Am I Gastroenterol 1999; 94: 131-8.

25 Walter S, Bodemar G, Hallbook O, Thorell LH. Sympathetic (electrodermal) activity during repeated maximal rectal distensions in patients with irritable bowel syndrome and constipation. Neurogastroenterol Motil 2008; 20: 43-52.

26 Hasler WL, Saad RJ, Rao SS, Wilding GE, Parkman HP, Koch KL,
Mccallum RW, Kuo B et al. Heightened colon motor activity measured by a wireless capsule in patients with constipation: relation to colon transit and IBS. Am I Physiol Gastrointest Liver Physiol 2009; 297: G1107-14.

27 Suttor VP, Prott GM, Hansen RD, Kellow JE, Malcolm A. Evidence for pelvic floor dyssynergia in patients with irritable bowel syndrome. Dis Colon Rectum 2010; 53: 156-60.

28 Ansari R, Sohrabi S, Ghanaie O, Amjadi $\mathrm{H}$, Merat S, Vahedi $\mathrm{H}$, Khatiban M. Comparison of colonic transit time between patients with constipation-predominant irritable bowel syndrome and functional constipation. Indian $I$ Gastroenterol 2010; 29: 66-8.

29 Patcharatrakul T, Gonlachanvit S. Outcome of biofeedback therapy in dyssynergic defecation patients with and without irritable bowel syndrome. I Clin Gastroenterol 2011; 45: 593-8.

30 Bouchoucha M, Devroede G, Raynaud JJ, Bon C, Bejou B, Benamouzig $\mathrm{R}$. Is the colonic response to food different in IBS in contrast to simple constipation or diarrhea without abdominal pain? Dig Dis Sci 2011; 56: 2947-56

31 Shekhar C, Monaghan PJ, Morris J, Issa B, Whorwell PJ, Keevil B, Houghton LA. Rome III functional constipation and irritable bowel syndrome with constipation are similar disorders within a spectrum of sensitization, regulated by serotonin. Gas troenterology 2013; 145: 749-57; quiz e13-4.

32 Bouchoucha $M$, Hejnar M, Devroede G, Boubaya M, Bon C, Benamouzig R. Patients with irritable bowel syndrome and constipation are more depressed than patients with functional constipation. Dig Liver Dis 2014; 46: 213-8.

33 Park SY, Park HB, Lee JM, Lee HJ, Park CH, Kim HS, Choi SK, Rew JS. Relevance of colonic gas analysis and transit study in patients with chronic constipation. I Neurogastroenterol Motil 2015; 21: 433-9.

34 Bouchoucha M, Devroede G, Bon C, Mary F, Bejou B, Benamouzig R. Difficult defecation in constipated patients and its relationship to colonic disorders. Int I Colorectal Dis 2016; 31: 685-91.

35 Costedio MM, Coates MD, Brooks EM, Glass LM, Ganguly EK, Blaszyk $\mathrm{H}$, Ciolino $\mathrm{AL}$, Wood $\mathrm{MJ}$ et al.
Mucosal serotonin signaling is altered in chronic constipation but not in opiate-induced constipation. Am I Gastroenterol 2010; 105: 1173-80.

36 Coates MD, Mahoney CR, Linden DR, Sampson JE, Chen J, Blaszyk H, Crowell MD, Sharkey KA et al. Molecular defects in mucosal serotonin content and decreased serotonin reuptake transporter in ulcerative colitis and irritable bowel syndrome. Gastroenterology 2004; 126: 1657-64.

37 Camilleri M, Andrews CN, Bharucha AE, Carlson PJ, Ferber I, Stephens D, Smyrk TC, Urrutia R et al. Alterations in expression of p11 and SERT in mucosal biopsy specimens of patients with irritable bowel syndrome. Gastroenterology 2007; 132: 17-25.

38 Surrenti E, Rath DM, Pemberton JH, Camilleri M. Audit of constipation in a tertiary referral gastroenterology practice. Am I Gastroenterol 1995; 90: $1471-5$.

39 Ratuapli SK, Bharucha AE, Noelting J, Harvey DM, Zinsmeister AR. Phenotypic identification and classification of functional defecatory disorders using high-resolution anorectal manometry. Gastroenterology. 2012; 144: 324-22.

40 Grossi U, Carrington EV, Bharucha AE, Horrocks EJ, Scott SM, Knowles $\mathrm{CH}$. Diagnostic accuracy study of anorectal manometry for diagnosis of dyssynergic defecation. Gut 2016; 65: 447-55.

41 Chiarioni G, Salandini L, Whitehead WE. Biofeedback benefits only patients with outlet dysfunction, not patients with isolated slow transit constipation. Gastroenterology 2005; 129: 86-97.

42 Chiarioni G, Whitehead WE, Pezza V, Morelli A, Bassotti G. Biofeedback is superior to laxatives for normal transit constipation due to pelvic floor dyssynergia. Gastroenterology 2006; 130: $657-64$

43 Le Neve B, Brazeilles R, Derrien M, Tap J, Guyonnet D, Ohman L, Törnblom H, Simrén M. Lactulose challenge determines visceral sensitivity and severity of symptoms in patients with irritable bowel syndrome. Clin Gastroenterol Hepatol 2016; 14: 226 33.

44 Tornblom H, Van Oudenhove L, Tack J, Simren M. Interaction between preprandial and postprandial rectal sensory and motor abnormalities in IBS. Gut 2014; 63: 1441-9. 
45 Van Oudenhove L, Tornblom H, Storsrud S, Tack J, Simren M. Depression and somatization are associated with increased postprandial symptoms in patients with irritable bowel syndrome Gastroenterology. 2016; 150: 866-74.

46 Rao SS, Seaton K, Miller M, Brown K, Nygaard I, Stumbo P, Zimmerman B,
Schulze K. Randomized controlled trial of biofeedback, sham feedback, and standard therapy for dyssynergic defecation. Clin Gastroenterol Hepatol 2007; 5: 331-8.

47 Ford AC, Moayyedi P, Lacy BE, Lembo AJ, Saito YA, Schiller LR, Soffer EE, Spiegel BM et al. American
College of Gastroenterology monograph on the management of irritable bowel syndrome and chronic idiopathic constipation. Am J Gastroenterol 2014; 109 Suppl 1: S2-26; quiz S7. 